\title{
Association Between the Phenotypes of Haptoglobin and Tuberculosis in Ivory Coast-Haptoglobin Phenotypes and Tuberculosis
}

\author{
Kone Fatoumata ${ }^{1,3}$, Hugues F T Ahiboh ${ }^{1,3}$, Joelle A Sibli-Koffi ${ }^{1}$, Mamadou Traore ${ }^{1}$, Jean-L K Konan ${ }^{3}$, Mohamed B O \\ Zein $^{2}$, Houphouët Yapi ${ }^{2}$, Djaman Joseph ${ }^{2}$, Medard Domoua ${ }^{4}$, Hervé Menan ${ }^{1}$ \\ ${ }^{1} \mathrm{CeDReS}$ - CHU Treichville, Abidjan, Côte d'Ivoire \\ ${ }^{2}$ Laboratory of de Pharmacology-Biochimistry, UFR of Biosciences UFHB, Abidjan, Côte d'Ivoire \\ ${ }^{3}$ Départment of Biochimistry and molecular biology, UFR SPB-UFHB, Abidjan, Côte d'Ivoire \\ ${ }^{4}$ Service de Pneumopthysiology Service of CHU deTreichville, Côte d'Ivoire \\ Correspondance: Kone Fatoumata, PV34 Abidjan; Département de Biochimie et Biologie Moléculaire, UFR des \\ Sciences Pharmaceutiques et Biologiques, Université Félix Houphouët Boigny, Côte d'Ivoire. \\ Email: kaunefatou@yahoo.fr
}

Received: July 30, 2018 Accepted: August 26, 2018 Online Published: August 28, 2018

doi:10.5539/ijc.v10n3p107 URL: https://doi.org/10.5539/ijc.v10n3p107

\begin{abstract}
The susceptibility of patients to certain pathologies, such as tuberculosis (TB), is associated to the phenotype of their haptoglobin (Hp). The objective of this study was to investigate the prognostic value of the haptoglobin phenotype in tuberculosis by determining the association of $\mathrm{Hp}$ phenotypes with certain epidemiological and clinical characteristics of tuberculosis in Côte d'Ivoire. In a case-control study, 131 tuberculosis and 109 non-tuberculosis as controls, voluntary blood donors were recruited in Abidjan. From venous blood samples, phenotyping of $\mathrm{Hp}$ was performed by polyacrylamide gel electrophoresis according to Raymond's method. Comparisons were made using chi2 test at risk $\alpha=$ $5 \%$. We found three phenotypes: Hp1-1, Hp2-1, Hp2-2 in the respective proportions of $27.5 \%, 50.5 \%$ and $22 \%$ in the control population $(\mathrm{n}=109)$ and $36.6 \%, 54.2 \%$ and $9.2 \%$ in the tuberculosis population $(\mathrm{n}=131)$. Among the population carrying the $\mathrm{Hp}^{1}$ allele, $58.3 \%$ were tuberculosis patients compared to $41.7 \%$ in controls subject $(\mathrm{p}=0.006)$. Among TB patients, 33.3\% carried Hp2-2 subtype compared to 66.7\% in controls $(\mathrm{p}=0.011)$. The Hardy-Weinberg's equilibrium showed that tuberculosis patients carring Hp2-2 phenotype died early. Hp phenotype was not associated to TB-HIV co-infection, neither to TB treatment nor to response to anti-tuberculosis treatment. We concluded that there is an association between Hp phenotype and TB infection prognosis. Hp2-2, less antioxidant seemed to be associated to the disease with poor prognosis.
\end{abstract}

Keywords: haptoglobin, phenotype, tuberculosis, Ivory Coast

\section{Introduction}

Haptoglobin (Hp) is a glycoprotein with antioxidant and immune modulatory properties in humans (Franck et al., 2001; Mark \& David, 2016). Three major phenotypes are found (Hp 1-1, Hp 2-1 and Hp 2-2) (Langlois \& Delanghe 1996; Yano, Yamamoto, Miyaishi \& Ishuzu, 1998), each of which has a functional specificity that can have a different impact on the prognosis of certain pathologies (Franck et al., 2001; Sadzadeh \& Bozorgmehr., 2004; Mark \& David, 2016). Hp binds with hemoglobin $(\mathrm{Hb})$ and both form an $\mathrm{Hp}-\mathrm{Hb}$ complex that plays an important role in the defense of the organism; while iron is necessary for bacterial growth, it's binding by the $\mathrm{Hp}-\mathrm{Hb}$ complex reduces its extra-erythrocyte availability and slows down the bacterial growth (Easton, Brandt, Mahoney \& Lee., 1992; Barclay, 1985; McDemid \& Prentice, 2006; Mark \& David, 2016).

A clinical-epidemiological specificity was reported based on the populations (Franck et al., 2001, Sadzadeh \&Bozorgmehr, 2004). Few studies reported the causes of these variations, particularly those inherent in ethno-genetic factors of the host. Therefore, the susceptibility of patients to certain pathologies including tuberculosis (TB) could be associated to the phenotype of their Hp. Studies have shown that tuberculosis subjects with Hp2-2 phenotype have an increased risk of mortality and increased susceptibility to developing severe renal tuberculosis compared to other phenotypes (Fedoseava, Lusopova, Chukanova \& Pospelov, 1993; Kasvosve et al., 2000). The prevalence of tuberculosis in Côte d'Ivoire is around 661 cases / 100000 inhabitants (Programme national de lutte contre la tuberculose [PNLT], 2012) and also has specific features (PNLT, 2012). In this study, we sought to determine the 
association between Hp phenotypes and certain epidemical and clinical characteristics of TB in Côte d'Ivoire.

\section{Material and Methods}

\subsection{Type of Study}

We performed a case-control study comparing the distribution and characteristics of Hp phenotypes in tuberculosis and healthy subjects.

\subsection{Population and Study Environment}

The study population were TB patients (beginning and ending) receiving treatment at the Anti- Tuberculosis Center of Treichville (ATCT) and voluntary blood donors from the National Blood Transfusion Center (CNTS). For each of the patients included, the survey card containing the variables of the study was filled, followed by a venous blood sampling on a tube containing lithium heparinate. Phenotyping of Hp were carried out at the Center for Diagnosis and Research on AIDS and other infectious diseases (CeDReS). Thus, we recruited $131 \mathrm{~TB}$ patients receiving treatment at CATT Abidjan and 109 voluntary blood donors from the CNTS.

\subsection{Method of Analysis}

The variables in this study were: Hp phenotype, sex, age, smear, clinical status (x-ray of the lungs), response to anti-tuberculosis treatment and presence of HIV / AIDS co-infection. Patient's data were obtained by history and from the respective medical records. The biological specimen was whole blood obtained through venipuncture on a heparinized tube. The plasma obtained after centrifugation was used for the phenotyping of Hp by electrophoresis of the $\mathrm{Hp}-\mathrm{Hb}$ complex in 5\% polyacrylamide gel (PAGE) (Raiymond, 1962).

\subsection{Consent and Ethical Approval}

The study was conducted with the authorization from the National Health authorities and the administrative head of the health center. We obtained an ethical clearance from the board of physicians of the center. All authors declare that 'written informed consent was obtained from the patient for publication of this paper and accompanying images.

\subsection{Statistical Analysis}

The data collected was entered using SPSS Software v16.0. The proportions of Hp phenotypes obtained were expressed as percentage and compared between the two study populations: tuberculosis patients and healthy subjects. The statistical analysis was carried out using the same software and the comparisons were made by the Chi - Square test. The distribution of alleles in the study populations was evaluated using Hardy Weinberg's equilibrium. The significance threshold was set at $5 \%$.

\section{Results}

\subsection{Demographics Characteristics}

In this study, we recruited 240 subjects comprising of 109 non-tuberculosis to serve as controls subjects and 131 tuberculosis patients. The 109 controls included $81.7 \%$ male and $18.3 \%$ female. Their mean age was $34.4 \pm 8.2$ years with extremes of 18 and 50 years. The tuberculosis population comprised $75.6 \%$ men and $24.4 \%$ women, their mean age was $36.10 \pm 11.83$ years with the extremes of 16 and 74 . This predominance of male subjects was statistically significant $(\mathrm{p}=0.009)$.

\subsection{Haptoglobin Phenotyping}

Three Hp phenotypes were found in the following proportions: Hp1-1 (37.5\%), Hp2-1 (50.5\%) and Hp2-2 (22\%) in controls and Hp1-1 (36,6\%), Hp2-1 (54.2\%) and Hp2-2 (9.2\%) in tuberculosis patients. The $\mathrm{Hp}^{1}$ allele represented $40.7 \%$ and $59.3 \%$ against $52 \%$ and $48 \%$ for the $\mathrm{Hp}^{2}$ allele in controls and tuberculosis patients respectively. So, subjects with $\mathrm{Hp}$ 2-2 were predominantly observed in the control population whereas those with Hp 1-1 and 2-1 phenotypes were observed among the tuberculosis subjects $(\mathrm{p}=0.014)$ (Table 1$)$. Thus, $\mathrm{Hp}^{1}$ allele was predominantly found in tuberculosis patients $(\mathrm{p}$ $=0.005)$ while $\mathrm{Hp}^{2}$ was more frequent in the control population $(\mathrm{P}=0.010)$ (Table 1). The distribution of these alleles in the population of the tuberculosis subjects was not in the Hardy-Weinberg's equilibrium $\left(X^{2}=17.53, p<0.0001\right)$; however, in the control population it was in the Hardy-Weinberg's equilibrium $\left(\mathrm{X}^{2}=0.52, \mathrm{p}=0.48\right)$.

\subsection{Tuberculosis Infection Location, Treatment and HIV Co-Infection}

Concerning the localization of tuberculosis infection, we found 126 pulmonary TB and 05 extra-pulmonary TB. There was no significant association between the Hp phenotype and the smear microscopic analysis result $(\mathrm{p}=0.051)$ (Table 2). High positive smear results (1-3 plus) were found in the Hp1-1 and 2-1 phenotype groups ( $\mathrm{p}=0.011$ ) (Figure 1).

We did not find any significant link regarding the Hp phenotype either with the treatment lines or with the frequency of TB-HIV co-infections (Table 3). 


\section{Discussion}

This study has enabled us establish the distribution of Hp phenotypes and $\mathrm{Hp} 1$ and 2 alleles in healthy and tuberculosis populations in Côte d'Ivoire.

Three Hp phenotypes were found. The Hp profiles observed were similar to those reported by Sukaina et al (2015) and Philemond et al (2017); but different from those of Constans, Viau, Gouaillard, and Clerc. (1981),that reported, in addition to these 3 phenotypes, phenotypes $\mathrm{Hp} 0-0$ and $\mathrm{Hp} 2-1 \mathrm{M}$ in Côte d'Ivoire. Bagat et al. (2015) found Hp0-0 phenotype in many Indians populations. The phenotype Hp0-0 is present in subjects who have anhaptoglobinemia (KoDH et al., 2013). When comparing our results to those of Sutton et al (1959), they agree on the phenotype profile of Hp (3 phenotypes), but according to that team, the $\mathrm{Hp} 1$ allele was $70 \%$ in Ivorian and Liberian populations, that means a higher frequency than what is observed in our study. These changes in the distribution of Hp phenotypes and alleles in Côte d'Ivoire could be explained, due to several displacements and mingle up of the populations since the first studies performed in 1958. It is therefore necessary to renew the study of Hp profile in the Ivorian population on a larger population sample recruited in several regions.

The subtype Hp 2-2 were predominantly observed in the control population whereas subtypes Hp 1-1 and 2-1 phenotypes were more frequent in the tuberculosis subjects $(\mathrm{p}=0.014)$. The Hp1 allele was predominantly found in tuberculosis patients $(\mathrm{p}=0.005)$ and $\mathrm{Hp} 2$ allele was more common in the controls population $(\mathrm{P}=0.010)$. These two results indicated the same trend which was similar to those of Kaminskaia, Abdullaev, Elufimova, Mitinskaia, and Iukhimenko (2004) and Philemond et al. (2017). However, they differed from what reported by many previous studies in which the Hp2-2 phenotype is less protective and therefore more expected to be found in patients than in controls (Langlois \& Delanghe , 1996, McDermid \& Prentice, 2006; Kasvosve et al., 2000).

The distribution of these alleles in the control population respected the Hardy-Weinberg's equilibrium $\left(\mathrm{X}^{2}=0.52, \mathrm{p}=\right.$ 0.48 ), which expresses the random nature of this distribution. Failure to observe this equilibrium in the tuberculosis population $\left(\mathrm{X}^{2}=17.53, \mathrm{p}<0.0001\right)$ proved the non-random nature of this distribution. This genetic drift in tuberculosis patients could be explained by the increased mortality of tuberculosis among carriers of Hp2-2 phenotype. This result indicated that, Hp2-2 phenotype was less in tuberculosis patients because the prognosis is worse for them and may be they died early than those who have phenotype 1-2 and 1-1. This result could be confirmed by the results of Kaminskaia et al. (2004) who found no carrier of Hp 2-2 phenotype in TB pediatric patients with tuberculous pleurisy. The appearance of pleurisy is a sign of severity of tuberculosis. The carriers of the phenotype Hp 2-2 do not therefore reach this stage; hence their absence in this group.

Concerning the localization of the tuberculosis infection, we found 126 cases of Pulmonary TB and 05 Extra-pulmonary TB. There was no significant association between the phenotype of Hp and the smear microscopic examination result (p $=0.051)$. The p-value very close to the threshold of statistical significance deserves to be confirmed on a larger sample population or on a population of heterogeneous tuberculosis from several sites in order to favor a random distribution of the Hp alleles. This result disagrees with those of the Kasvosve et al (2000) study on tuberculosis patients High positive (1 to 3 cross) microscopies were found in groups of Hp1-1 and 2-1 phenotypes but this was not statistically significant.

We did not find any significant link in the Haptoglobin phenotype with neither the treatment lines, nor with the frequency of TB-HIV co-infections. Similar results were reported (Zaccarioto et al., 2006).

Nevertheless, we have not obtained enough studies of less than 5 to 10 years on this theme.

\section{Conclusion}

Three phenotypes of Hp were found in Côte d'Ivoire: Hp1-1, Hp2-1 and Hp2-2. There was an association between the phenotype of $\mathrm{Hp}$ and the frequency of TB infection. Thus, the predominant distribution of the Hp1 allele in tuberculosis subjects was not random and Hp2-2, less antioxidant was associated with TB poor prognosis. The presence of allele $\mathrm{Hp}^{2}$ seemed to be associated with a high rate on mortality of TB. The Hp phenotype was not associated with microscopy, HIV-TB co-infection, tuberculosis treatments or response to these treatments. 
Table 1. Distribution of Hp phenotypes and alleles in the study population

\begin{tabular}{llll}
\hline $\begin{array}{l}\text { CASE } \\
(\mathbf{n = 1 3 1})\end{array}$ & CONTROL $(\mathbf{n = 1 0 9 )}$ & p-Value \\
\hline \multicolumn{2}{l}{ Phenotype of Hp } & & \\
\hline $\mathbf{1 - 1}$ & $\mathbf{4 8}(\mathbf{3 6 , 6 \%})$ & $30(37,5 \%)$ & \\
$\mathbf{2}-\mathbf{7 1}$ & $\mathbf{7 1}(\mathbf{5 4 , 2 \%})$ & $55(50,5 \%)$ & $\mathbf{0 , 0 1 4}$ \\
$\mathbf{2}-2$ & $12(9,2 \%)$ & $\mathbf{2 4}(\mathbf{2 2 , 0 \% )}$ & \\
\hline Alleles & & & $\mathbf{0 , 0 0 5}$ \\
\hline Hp1 & $\mathbf{1 1 9}(\mathbf{9 0 , 8 \% )}$ & $85(78,0 \%)$ & $\mathbf{0 , 0 1 0}$ \\
Hp2 & $12(9,2 \%)$ & $\mathbf{2 4}(\mathbf{2 2 , 0 \%})$ & \\
\hline
\end{tabular}

n =population, $\%=$ percentage

Table 2. Distribution of microscopic results in the study population

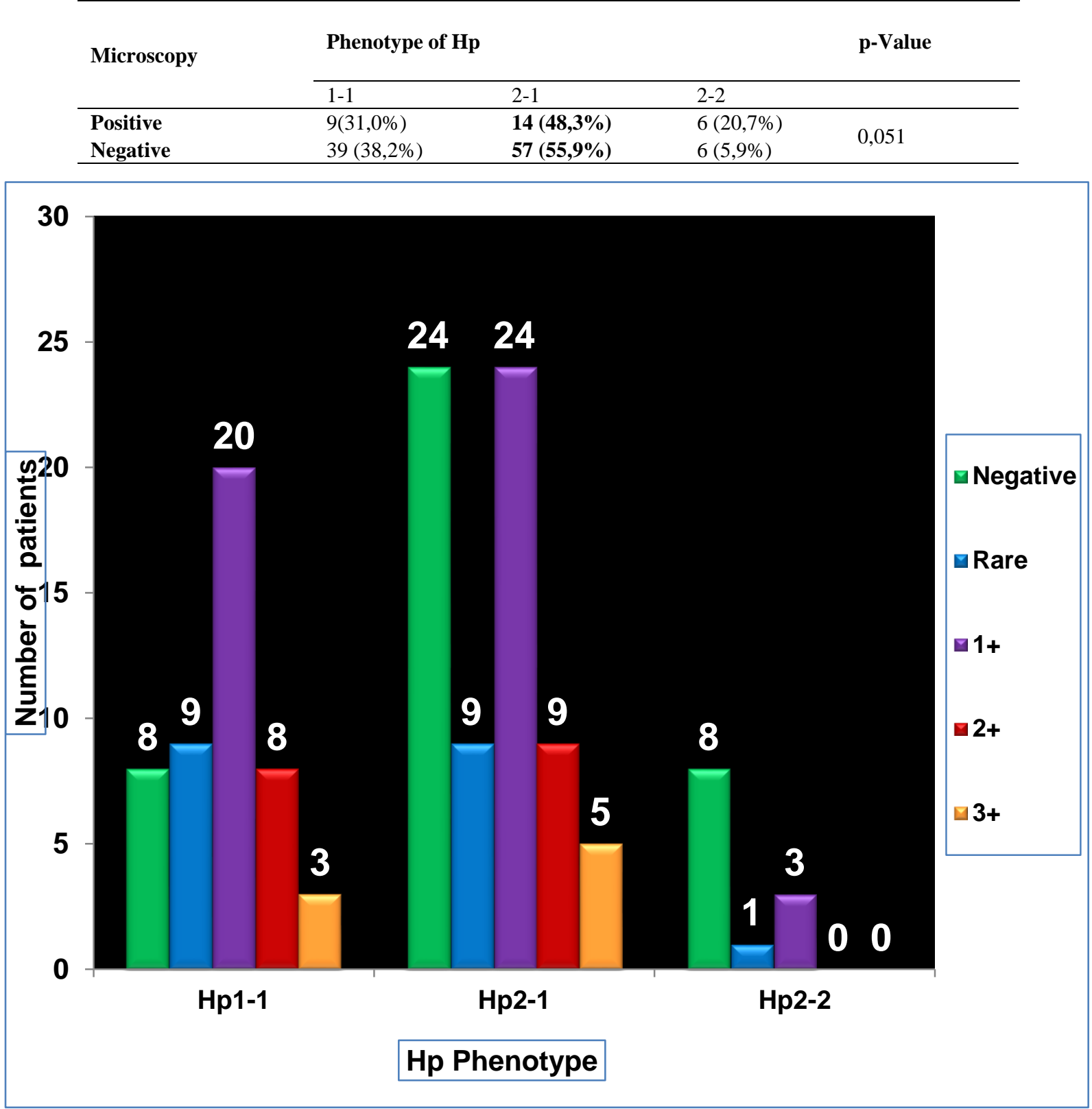

Figure 1. Analysis of diagnostic smear according to Hp phenotypes

BARR : bacilles acido-alcoolo resistants ; CM=Microscopic field; Negative: No BARR/CM; Rare: <1 BARR/CM ;1+: 1 à 9 BARRS/CM; 2+: 10 à 99 BARRS/CM ;3+: $\geq 100$ BARRS/CM 
Table 3. Distribution of clinical-therapeutic characteristics between Hp phenotypes

\begin{tabular}{|c|c|c|c|c|}
\hline & \multicolumn{3}{|l|}{ Hp phenotypes } & \multirow[t]{2}{*}{ p-Value } \\
\hline & $1-1$ & $2-1$ & $2-2$ & \\
\hline \multicolumn{5}{|l|}{ Therapy [n (\%)] } \\
\hline $\begin{array}{l}\text { Line } 1 \\
\text { (RHZE / RH ; } 6 \text { months) }\end{array}$ & $36(37,9 \%)$ & $52(54,7 \%)$ & $7(7,4 \%)$ & \multirow{3}{*}{0,502} \\
\hline $\begin{array}{l}\text { Line } 2 \\
\text { (SRHZE / RHZE / RH ; } 8 \text { months) }\end{array}$ & $12(33,3 \%)$ & $19(52,8 \%)$ & $5(13,9 \%)$ & \\
\hline Total & $48(36,6 \%)$ & $71(54,2 \%)$ & $12(9,2 \%)$ & \\
\hline \multicolumn{5}{|l|}{ FALLEN BACK OR FAILURE [n (\%)] } \\
\hline YES & $12(34,3 \%)$ & $18(51,4 \%)$ & $5(14,3 \%)$ & \multirow{2}{*}{0,470} \\
\hline NO & $36(37,5 \%)$ & $53(55,2 \%)$ & $7(7,3 \%)$ & \\
\hline \multicolumn{5}{|l|}{ TB-HIV CO-INFECTION [n (\%)] } \\
\hline $\begin{array}{l}\text { YES } \\
\text { NO }\end{array}$ & $\begin{array}{l}7(24,1 \%) \\
41(40,2 \%)\end{array}$ & $\begin{array}{l}19(65,5 \%) \\
52(51,0 \%)\end{array}$ & $\begin{array}{l}3(10,3 \%) \\
9 \quad(8,8 \%)\end{array}$ & 0,283 \\
\hline
\end{tabular}

$\mathbf{R}:$ Rifampicine, H: Isoniazide, E: Etambutol, Z: Pyrazinamide, S: Streptomycine

\section{References}

Bapat, P. R., Satav, A. R., Husain, A. A., Shekhawat, S. D., Kawle, A. P., Chu, J. J., \& Kashyap, R. S. (2015). DifferentialLevelsofAlpha-2-Macroglobulin, Haptoglobin and Sero-Transferrin as Adjunct Markers for TB Diagnosis and Disease Progression in the Malnourished Tribal Population of Melghat,India. PLoSONE, 10(8), 1-17, e0133928.

Barclay, R. (1985). The role of iron in infection. Med. Lab. Sd., 42, 166-77. PMID: 2933571

Constans, J., Viau, M., Gouaillard, C., \& Clerc, A. (1981). Haptoglobin Polymorphism among Saharian and West African Groups Haptoglobin Phenotype Determination by Radioimmuno electro phoresis on Hp 0 Samples. American Journal of Human Genetics, 33, 606-616. No 0002-9297/81/33040012\$02.00

Eaton, J. W., Brandt, P., Mahoney, J. R., \& Lee, J. T. (1982). Haptoglobin: a natural bacteriostat. Science, 215, 691-693. PMID: 7036344. https://doi.org/10.1126/science.7036344

Fedoseeva, S. V., Lusopova, M. M., Chukanova, V. P., \& Pospelov, L. E. (1993). Course of infiltrating pulmonary tuberculosis depending on the patient's genotype. Problemy Tuberkuleza, 2, 8-10, PMID: 7984577

Frank, M. M., Lache, O., Enav, B. I., Szafranek, T., Levy, N. S., Ricklis, R. M., \& Levy, A. P. (2001). Structurefunction analysis of antioxidant properties of haptoglobin. Blood, 98, 3693-3698. https://doi.org/10.1182/blood.V98.13.3693

Kaminskaia, G. O., Abdullaev, R. I., Elufimova,V. F., Mitinskaia, L. A., \& Iukhimenko, N. V. (2004). The phenotypes of haptoglobin and the level of acute-phasic proteins in the sera of children with local form of intrathoracic tuberculosis. Problemy Tuberkuleza i Boleznei Legkikh., 7, 35-40. PMID: 15379040

Kasvosve, I., Gomo, Z. A., Mvundura, E., Moyo, Y. M., Saungweme, T., Khumalo, H., \& Gangaidzo, L. T. (2000). Haptoglobin polymorphism and mortality in patients with tuberculosis. Internal Journal of Tuberculosis and Lung Disease, 4, 771-775. PMID: 10949330

Ko, D. H., Chang, H. E., Kim, T. S., Song, E. Y., Park, K. U., Song, J., \& Han, K. S. (2013). A Review of Haptoglobin Typing Methods for Disease Association Study and Preventing Anaphylactic Transfusion Reaction. BioMed Research International, 6. https://doi.org/10.1155/2013/390630

Langlois, M. R., \& Delanghe, J. R. (1996). Biological and clinical significance of haptoglobin polymorphism in humans. Clinical Chemistry, 42, 1589-600. PMID: 8855140

Mark, M., \& David, J. V. (2016). Role of Haptoglobin in Health and Disease: A Focus on Diabetes. Clinical. Diabetes Journals, 34(3), 148-157. https://doi.org/10.2337/diaclin.34.3.148

McDermid J. M., \& Prentice, A. M. (2006). Iron and infection: effects of host iron status and the iron-regulatory genes haptoglobin and NRAMP1 (SLC11A1) on host-pathogen interactions in tuberculosis and HIV, Clinical Science 110, 503-524. https://doi.org/10.1042/CS20050273

Philemond, B., Hugues, T. A., Joelle, A. S. K., Fatoumata, K., Hamadou, T., Mamadou, T., Medard, K. S. D., \& Dagui, M. (2017). Haptoglobin Phenotype and Soluble Transferrin Receptor among Tuberculosis British. Journal of Medicine \& Medical Research, 19(3), 1-7. https://doi.org/10.9734/BJMMR/2017/30095 
Programme National De Lutte Contre La Tuberculose (PNLT) Côte d'Ivoire (2012). Plan stratégique national 2012-2015 de lutte contre la tuberculose ; 65 pp

Raymond, S. (1962). A convenient apparatus for vertical gel electrophoresis. Clinical Chemistry, 8, 455-470.

Sadrzadeh, S. M., \& Bozorgmehr, J. (2004). Haptoglobin phenotypes in health and disorders. American Journal of Clinical Pathology, 121, 97-104. https://doi.org/10.1309/8GLX5798Y5XHQ0VW

Sukaina, A., Zeinab, A., Ashraf, S., Parinaz, G., Mojgan, B., Ali, A. M., \& Bahram, K. (2015). Determination of haptoglobin genotype in an Iranian population with idiopathic generalized epilepsy. Reports of Biochemistry \& Molecular Biology, 3, 52-55. PMID: 26989737

Sutton, B. E., Neel, J. V., Livingstone, F. B., Binson, G., Kunstadter, P., \& Trombley, L. E. (1959). The frequencies of haptoglobin types in five populations. Annal of Human Genetetics, 23, 175-183. https://doi.org/10.1111/j.1469-1809.1958.tb01460.x

Yano, A., Yamamoto, Y., Miyaishi, S., \& Ishuzu, H. (1998). Haptoglobin genotyping by allele specific polymerase chain reaction amplification. Acta. Med. Okayama., 52, 173-181. doi: 10.18926/AMO/31301

Zaccariotto, T. R., Rosim, E. T., Melo, D., Garcia, P. M., Munhoz, R. R., Aoki, F. H., \& Sonati, M. D. F. (2006). Haptoglobin polymorphism in a HIV-1 seropositive Brazilian population. Journal of Clinical Pathology, 59, 550553. https://doi.org/10.1136/jcp.2005.027375

\section{Copyrights}

Copyright for this article is retained by the author(s), with first publication rights granted to the journal.

This is an open-access article distributed under the terms and conditions of the Creative Commons Attribution license (http://creativecommons.org/licenses/by/4.0/). 